\title{
Price development of photovoltaic modules, inverters, and systems in the Netherlands in 2012
} \author{
Peer de Rijk ${ }^{a, f}$ \\ a Stichting Monitoring Zonnestroom (SMZ), Utrecht, The Netherlands \\ ${ }^{\mathrm{b}}$ Utrecht University, CopernicusInstitute, Utrecht, The Netherlands \\ ${ }^{\mathrm{c}}$ New-Energy-Works (NEW), Utrecht, The Netherlands \\ ${ }^{\mathrm{d}}$ Rencom, Ouderkerk a/d Amstel, The Netherlands \\ e Holland Solar, Utrecht, The Netherlands \\ ${ }^{\mathrm{f}}$ Organisatie voor Duurzame Energie (ODE), Utrecht, The Netherlands
}

Wilfried G.J.H.M. van Sark ${ }^{\mathrm{a}, \mathrm{b}}{ }^{\text {* }}$, Peter Muizebelt ${ }^{\mathrm{c}}$, Jadranka Cace ${ }^{\mathrm{d}}$, Arthur de Vries ${ }^{\mathrm{a}}$ e ,

\section{A R T I C L E I N F O}

\section{Article history:}

Received 5 December 2013

Accepted 8 May 2014

Available online 2 June 2014

\section{Keywords:}

PV market

Price development

Grid parity

PV module

Inverter

System

\begin{abstract}
A B S T R A C T
Since 2010 the Dutch photovoltaic (PV) market has been growing fast, with around doubling of installed capacity in 2011 and 2012. Four quarterly inventories have been made in 2012 for modules, inverters, and systems that are presently available for purchase in the Netherlands. We have found that the average selling price of modules, inverters, and systems decreased with $44.3,14$, and $7.3-10.2 \%$, respectively: average selling prices are $1.26 € / \mathrm{Wp}, 0.41 € / \mathrm{Wp}$, and $1.46 € / \mathrm{Wp}$ for modules, inverters, and systems on tilted roofs, respectively, at the end of 2012. Average installation costs amount to $0.43 € / \mathrm{Wp}$. Using an energy yield of $900 \mathrm{kWh} / \mathrm{kWp}, 25$ years system lifetime, 6\% discount rate, and $1 \%$ operation and maintenance (O\&M) cost, a levelized cost of electricity (LCOE) is calculated for a $2.5 \mathrm{kWp}$ system to be $0.194 € / \mathrm{kWh}$ for a system price of $1.98 € / \mathrm{Wp}$ (including installation). Grid parity conditions are apparent, with electricity retail prices of around $0.23 € / \mathrm{kWh}$.
\end{abstract}

() 2014 Elsevier Ltd. All rights reserved.

\section{Introduction}

Deployment of photovoltaic (PV) systems in the Netherlands has been irregular due to changing subsidy schemes, as is illustrated in Fig. 1. After a slow but steady capacity growth up to 2002, a very successful investment subsidy scheme (Energy Premium, EPR) lead to a near doubling of capacity in 2003. However, due to abolishment of this subsidy scheme, capacity growth was near zero for 4 years. A new scheme, based on a feed-in tariff was devised (Stimulation Renewable Energy production, SDE), which lead to a large capacity growth in 2009 and 2010. This was followed by a new scheme (SDE+), which, however, was much less favorable to PV as the 2000-2010 schemes. Nevertheless, market growth in 2011 was $57 \mathrm{MWp}$, again nearly doubling capacity to $145 \mathrm{MWp}$. In an earlier study [2], we showed that PV system prices were nearing grid parity at the end of 2011, which at least partly enabled market

\footnotetext{
* Corresponding author. Stichting Monitoring Zonnestroom (SMZ), Utrecht, The Netherlands.

E-mail addresses: w.g.j.h.m.vansark@uu.nl (W.G.J.H.M. van Sark), peter, muizebelt@new-energy-works.com (P. Muizebelt), jadranka@rencom.nl (J. Cace), adevries@celstar.nl (A.de Vries), peerder@gmail.com (P. de Rijk).
}

growth. We therefore extended our market study in the year 2012. The global development of module prices was expected to also influence Dutch module prices, which was corroborated by early 2012 market data [2]. In July 2012 a new investment subsidy became in force for residential PV owners (15\% subsidy on material investment costs up to a maximum of $650 €$ per system). However, right after the announcement in May 2012, market turnover dropped enormously, as consumers waited for final details on the subsidy scheme before making their purchase: this was referred to as 'consumer strike'. The subsidy scheme was questioned by the PV industry as it created yet another market imbalance. Nevertheless, capacity growth in 2012 was expected to at least doubling the cumulative installed capacity. Recently updated figures show that installed capacity has more than doubled to 340 MWp [1] (Fig. 1).

An inventory of the PV market in the Netherlands was made every quarter in 2012, by collecting price data on PV modules, inverters, other system components including installation and consultancy, in order to support private customers in their purchasing decision. VAT was therefore included in the price data. Moreover, for four different typically sized PV systems, performance and cost calculations were performed. This allowed to determine the 


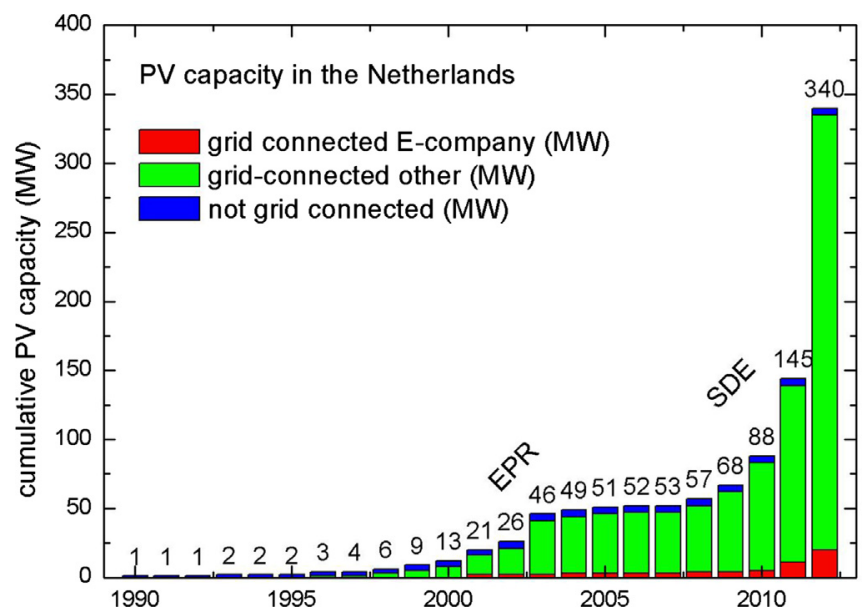

Fig. 1. Development of the cumulative installed PV capacity in the Netherlands (data source: CBS [1]).

levelized cost of electricity of PV systems in order to compare with retail electricity prize of typically $0.23 € / \mathrm{kWh}$, and assessment of consumer grid parity.

\section{Methodology}

The collection of market data was performed using extensive Internet searches that identified the relevant retailers of PV modules, inverters, complete systems, and other BOS components. For most of these retailers price data were available on their web sites. Those for which this information was not available were contacted directly (phone, email) and were asked to provide detailed price information on the products they sell, also including data on installation prices. Note that all prices in this paper are quoted including value-added tax (VAT), which was $19 \%$ prior to 1 October 2012 and $21 \%$ from that date onwards.

The levelized cost of electricity (LCOE) was calculated using

$\mathrm{LCOE}=\frac{\alpha I+\mathrm{OM}}{E}$

where $\alpha$ is the capital recovery factor, $I$ the initial investment, OM the operation and maintenance cost, and $E$ the annual electricity production. The capital recovery factor is defined as

$\alpha=\frac{r}{1-(1+r)^{-L}}$

with $r$ the discount rate, and $L$ the lifetime of the system.

In the Netherlands a large number of 4-6 module systems were installed, and still are offered: system size then is on average about $600 \mathrm{Wp}$. Nowadays, a typical household roof system measures about $2.5 \mathrm{kWp}$. As typical yields range from 800 to $1000 \mathrm{kWh} / \mathrm{kWp}$, depending on correct and optimal installation, such a system would generate $2000-2500 \mathrm{kWh}$ annually. This constitutes $57-71 \%$ to the annual electricity demand of an average Dutch household, i.e., $3500 \mathrm{kWh}$. Present legislation allows for net metering up to $5000 \mathrm{kWh}$ annually, therefore a $5-\mathrm{kWp}$ system is also taken as a size in our study. Larger systems range from 10 to $50 \mathrm{kWp}$. We have chosen four typical sizes for the LCOE calculation: 0.6, 2.5, 5, and $50 \mathrm{kWp}$. Operation and maintenance cost are taken as $1 \%$ of investment cost and reflect the usual change of the inverter once during the lifetime of the system of typically 25 years. A typical, mortgage-related interest rate is $6 \%$, while a lower, soft of green loan rate may be possible at $3 \%$. Commercial rates are $8 \%$ or higher. Results will be presented using these ranges of values.

\section{Results}

\subsection{PV modules}

In the quarterly inventories of PV modules the number of unique modules rose from 480 in April to 669 in December 2012, and these were predominantly crystalline silicon modules (49\% mono, $49 \%$ poly, $2 \%$ thin film). The average selling price decreased from $€ 442$ (range $€ 147-€ 921$ ) to $€ 287$ (range $€ 82-€ 840$ ); this translates into values of the price per rated power of $2.10 € / \mathrm{Wp}$ (range $0.95-6.69 € / \mathrm{Wp}$ ) and $1.26 € / \mathrm{Wp}$ (range $0.64-2.63 € / \mathrm{Wp}$ ) for April and December 2012, respectively. This development in price is shown in Fig. 2, where the error bars are the standard deviations in the mean values. Data from October 2011 are also shown for comparison. Clearly, a very large price decrease of $44.3 \%$ occurred between October 2011 and December 2012. Similar decreases have been reported globally. The number of modules with lower price than $1.1 € / \mathrm{Wp}$ increased from 10 in April 2012 to $84(17.5 \%)$ in December 2012. Thus, in the Netherlands, PV module price is observed to decrease between October 2011 and December 2012 with 7.5 cent $€$ every month. Note that the consumer strike of mid 2012 is reflected in the price trend as a relatively low price change in the fall of 2012.

Fig. 3 shows the changes in price distribution over the same period. The decrease in price can be cleary observed, as well as the narrowing of the distribution, which may be due to the fact that more expensive modules have been taken off the market. In fact, some $15 \%$ of the modules each quarter are new on the market.

\subsection{Inverters}

The number of inverters in the inventory rose from 188 in April to 342 in December 2012. The average selling price decreased from $€ 2013$ (range $€ 120-€ 7921$ ) to $€ 1823$ (range $€ 155-€ 7399$ ). Note that the range in rated capacity varies from $215 \mathrm{~W}$ to $60 \mathrm{~kW}$; this translates into values for the price per rated power of $0.48 € / \mathrm{Wp}$ (range $0.18-1.09 € / \mathrm{Wp}$ ) and $0.41 € / \mathrm{Wp}$ (range $0.17-0.92 € / \mathrm{Wp}$ ) for April and December 2012, respectively. The average EU efficiency is $95.2 \%$. Small size inverters are more expensive than large size ones: for size $<1 \mathrm{~kW}$ the average price is $0.6 € / \mathrm{Wp}$; for

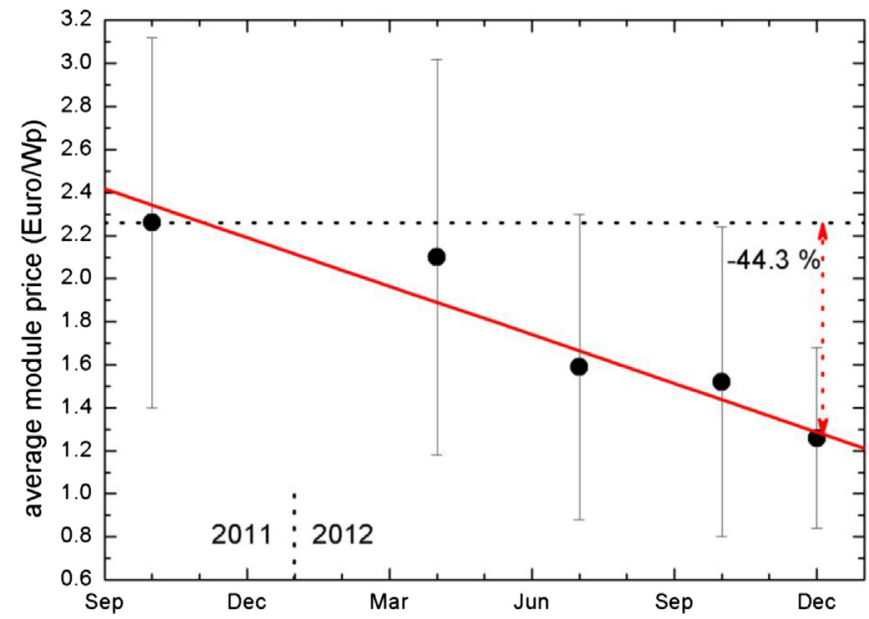

Fig. 2. Development of PV module price (including tax) between October 2011 and December 2012. 

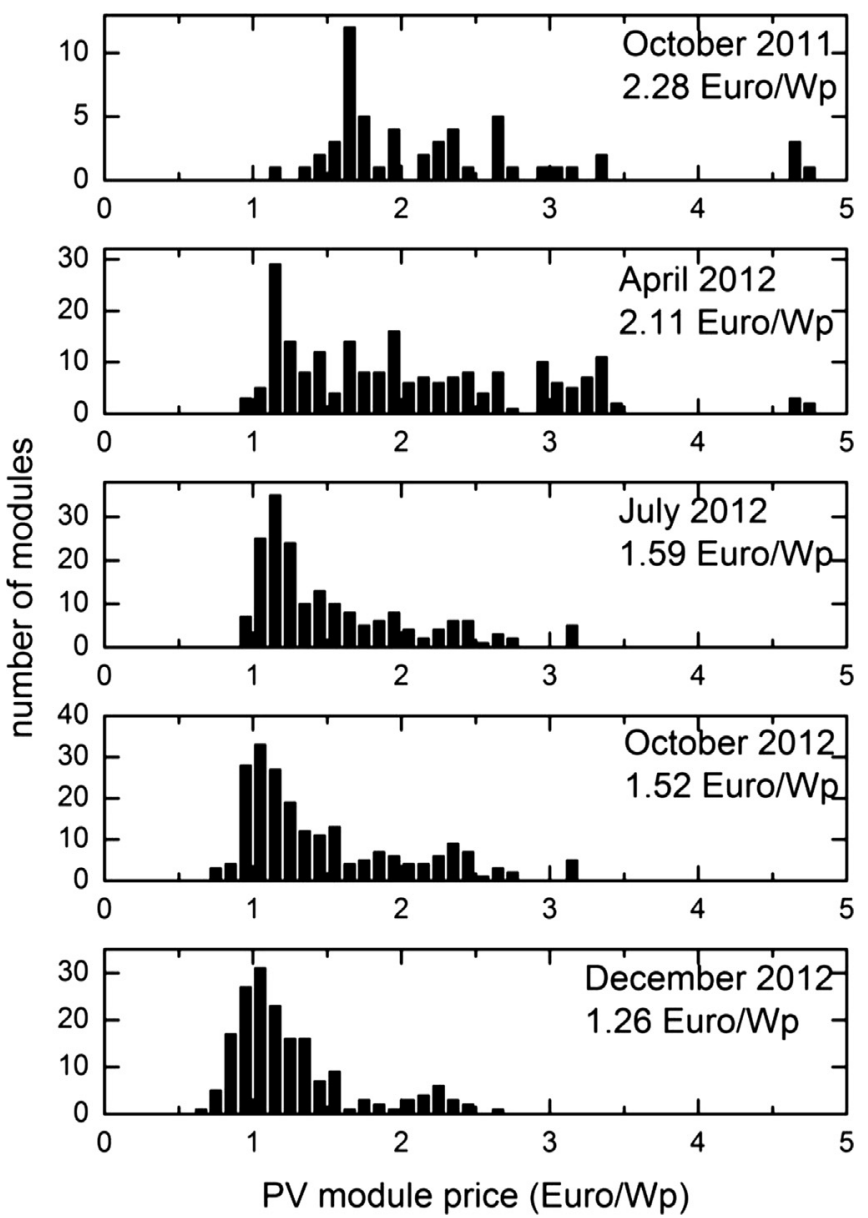

Fig. 3. Development of the distribution of PV module price (including tax) between October 2011 and December 2012.

inverters $>10 \mathrm{~kW}$ the price is $<0.3 € / \mathrm{Wp}$, as is illustrated in Fig. 4.The development in price is shown in Fig. 5, where the error bars are the standard deviations in the mean values. A modest decrease in price is observed of $14 \%$ occurred between April and December 2012, or 0.8 cent $€$ in this period.

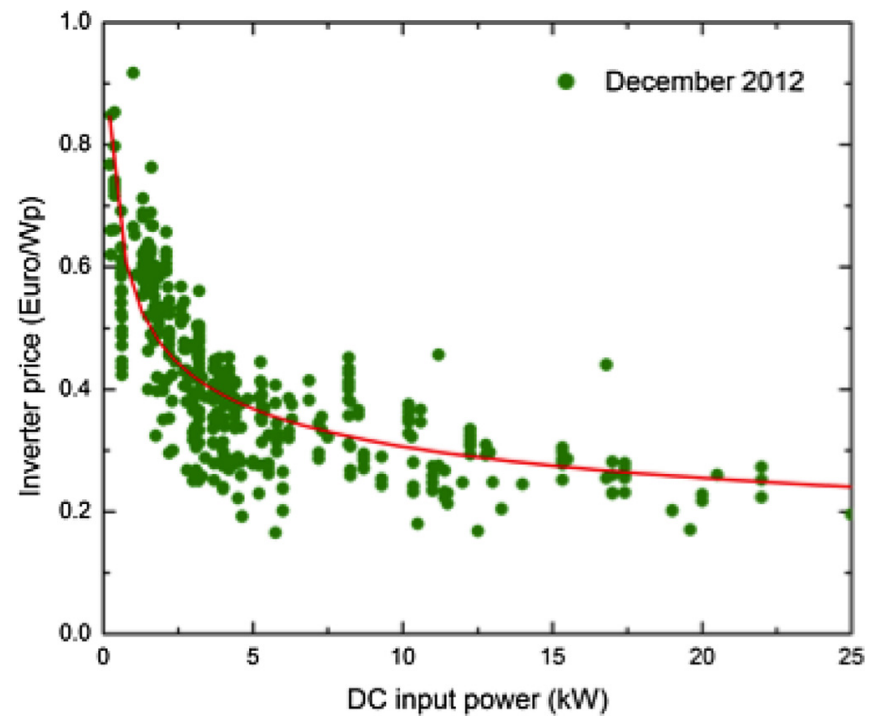

Fig. 4. Inverter price (including tax) as a function of DC input power for December 2012.

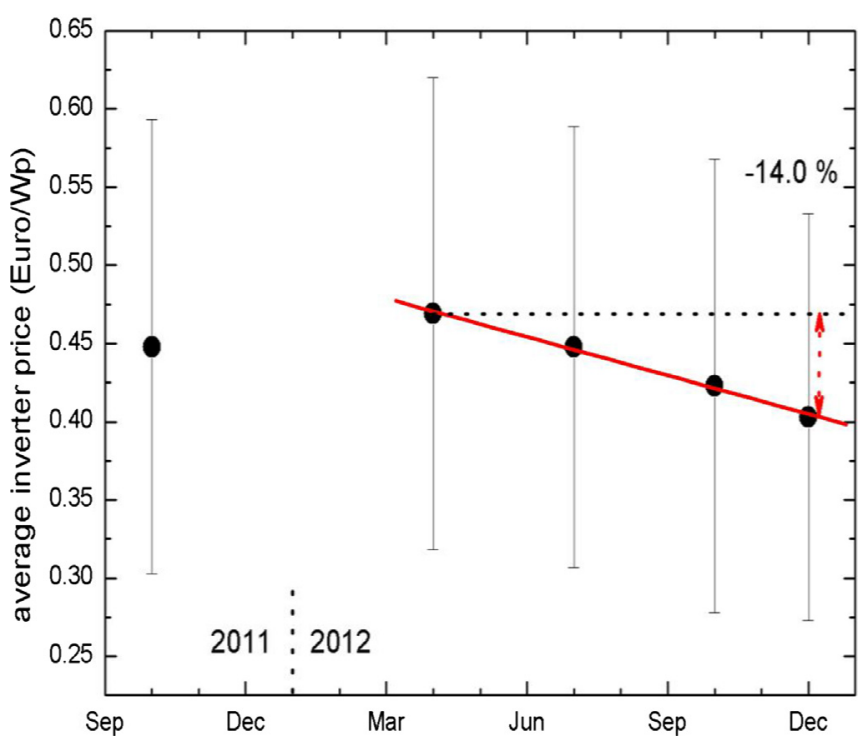

Fig. 5. Development of inverter price (including tax) between October 2011 and December 2012

\subsection{Systems}

The number of systems for tilted (flat) roofs in the inventory rose from 1557 (1477) in April to 2352 (2270) in December 2012. The average selling price for tilted systems decreased from 1.63 $€ / \mathrm{Wp}$ (range $1.28-4.44 € / \mathrm{Wp}$ ) to $1.46 € / \mathrm{Wp}$ (range $1.05-2.73$ $€ / W p$ ) in April and December 2012, respectively. Similar numbers, albeit slightly higher are found for flat roof systems. The price development is depicted in Fig. 6 for both tilted and flat roof systems. A decrease in price is observed of $10.2 \%$ for tilted systems (7.3\% for flat roof systems) between April and December 2012, or 2 (1.5) cent $€$ in this period. Note that the average selling price depends on system size: large systems have lower prices than small systems, as illustrated in Fig. 7. The average prices for three system size ranges have been determined, i.e., for $0-1 \mathrm{kWp}, 1-5 \mathrm{kWp}$, and 5-25 kWp, all excluding installation. Fig. 8 shows the price development for these ranges. For the smaller systems, the price decrease is clear; the price of the largest systems seems to stabilize.

Average installation costs have been determined to be 0.40 $€ / \mathrm{Wp}$ in July to $0.44 € / \mathrm{Wp}$ in December, as shown in Fig. 9. This

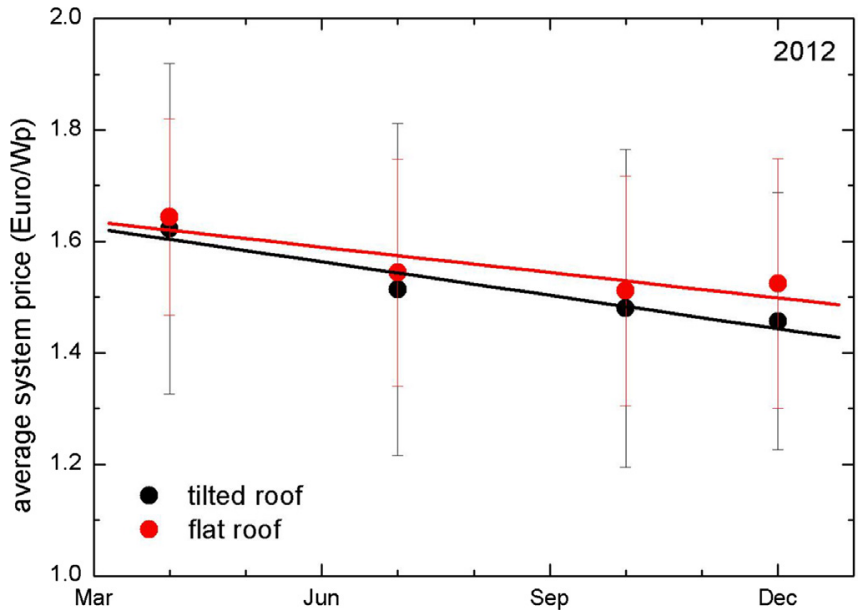

Fig. 6. Development of system price (including tax) for tilted and flat roof systems. 


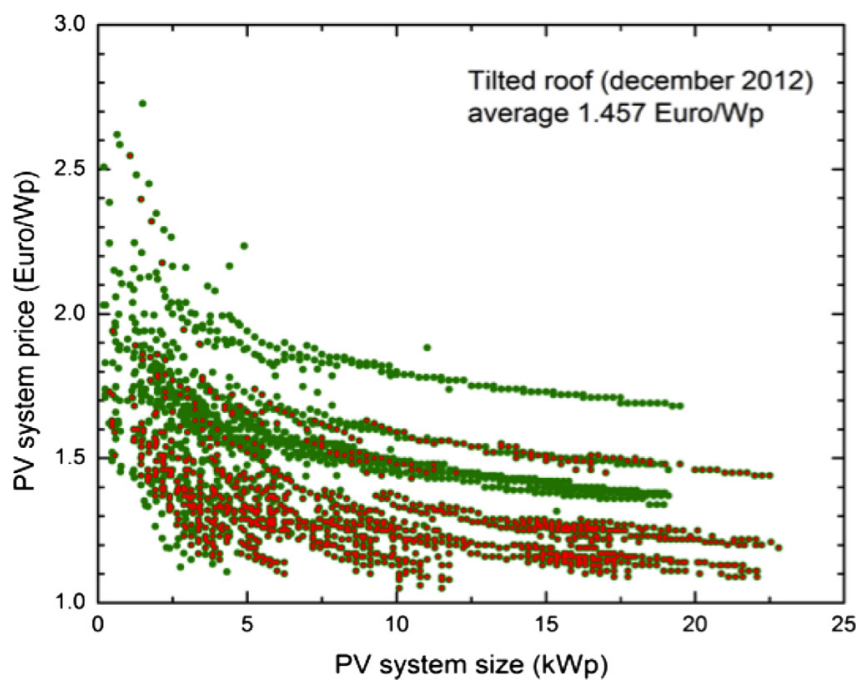

Fig. 7. System price in December 2012 for tilted systems, excluding installation.

may be caused by lowered system price margins being compensated somewhat by higher installation cost margins. Note that for small systems installation costs are $>0.50 € / \mathrm{Wp}$, while for large systems ( $>5 \mathrm{kWp}$ ) installation costs are $<0.30 € / \mathrm{Wp}$. Based on the December 2012 data, and the size dependent prices from Fig. 7, the system size dependent prices are set as shown in Table 1.

\subsection{LCOE for typical systems}

For the four system sizes, with associated prices, the LCOE is calculated for three different values of the interest rate. Results are shown in Table 2; the yellow marked values are similar or lower than the current (early 2013) price of electricity $(0.23 € / \mathrm{kWh})$ that utilities charge to customers. Clearly, as was found in the previous study as well [2], grid parity has been reached for systems between 2.5 and $5 \mathrm{kWp}$ for high energy rating values. For small systems and low energy ratings only soft and mortgage type loans lead to grid parity. Due to net metering legislation, systems larger than $5.5 \mathrm{kWp}$ (at $900 \mathrm{kWh} / \mathrm{kWp}$ ) are not considered to be operable below consumer grid parity. Also, consumers/owners installing systems of $50 \mathrm{kWp}$, most probably pay a much lower fee of about $0.10 € / \mathrm{kWh}$

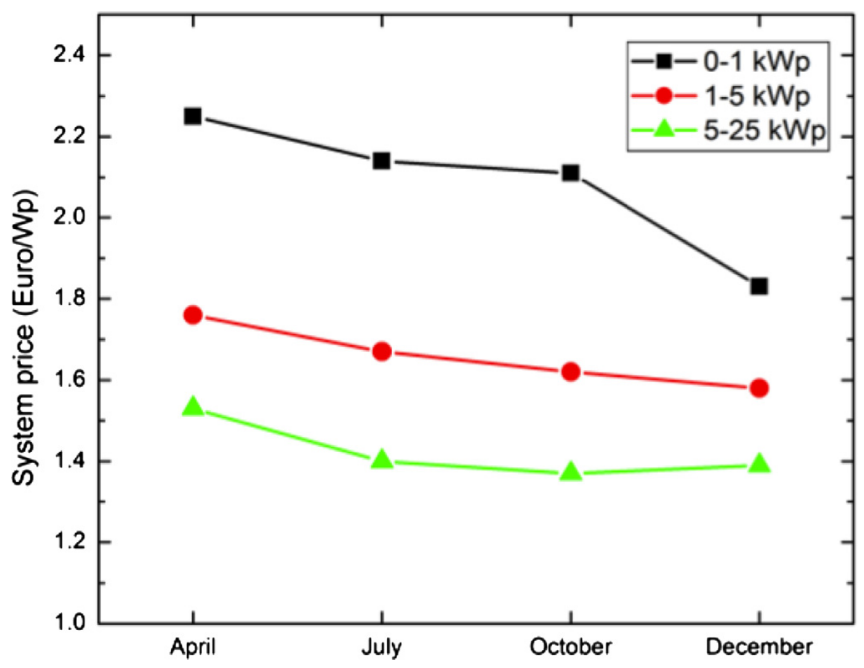

Fig. 8. Development of system price for three different size ranges.

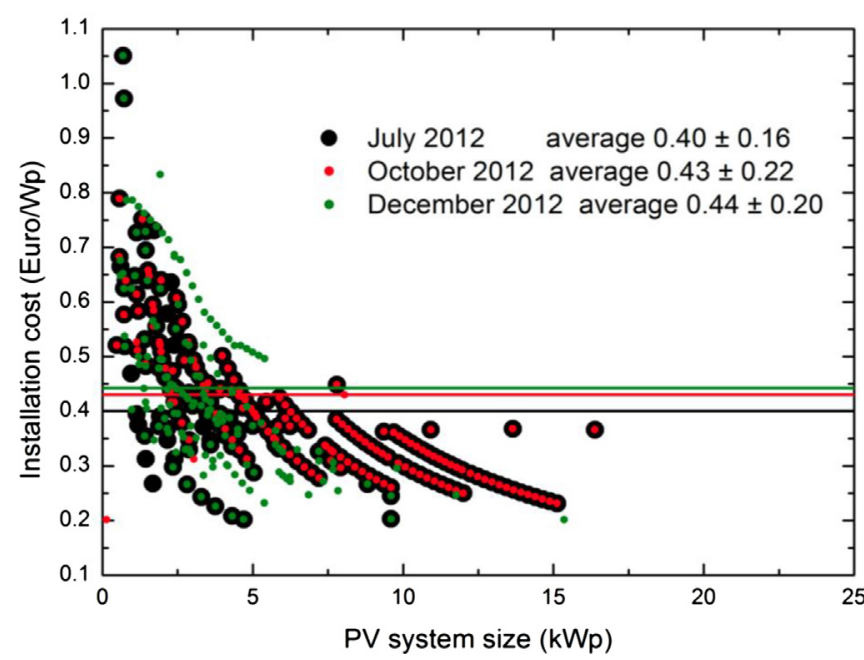

Fig. 9. Development of system installation cost between July 2012 and December 2012.

to utilities, as they are so-called large consumers (and in fact will be owners/tenants of office buildings). In their case, grid parity is not reached, and PV system price should be close to $1 € / \mathrm{Wp}$. Note, that new legislation in mid 2013 will probably remove the $5000 \mathrm{kWh}$ barrier, which would make larger residential installations more attractive in economical terms.

\section{Discussion}

The present study in fact is to been as a start of a long-term effort to follow market developments, which would allow identifying price trends much better. Nevertheless, the quarterly price

Table 1

Prices of four typically sized PV systems.

\begin{tabular}{llll}
\hline System size $(\mathrm{kWp})$ & Price $(€ / \mathrm{Wp})$ & Installation $(€ / \mathrm{Wp})$ & Total $(€ / \mathrm{Wp})$ \\
\hline 0.6 & 1.83 & 0.60 & 2.43 \\
2.5 & 1.58 & 0.40 & 1.98 \\
5 & 1.39 & 0.30 & 1.69 \\
50 & 1.39 & 0.20 & 1.59
\end{tabular}

Table 2

LCOE $(€ / \mathrm{kWh})$ for various combinations of energy yield, system size and price, and interest rate. Other assumption is $1 \%$ O\&M

\begin{tabular}{lcllll}
\hline $\begin{array}{l}\text { Energy yield } \\
(\mathrm{kWh} / \mathrm{kWp})\end{array}$ & Size $(\mathrm{kWp})$ & Price $(€ / \mathrm{Wp})$ & $3 \%$ & $6 \%$ & $8 \%$ \\
\hline 800 & 0.6 & 2.43 & 0.205 & 0.268 & 0.315 \\
& 2.5 & 1.98 & 0.167 & 0.218 & 0.257 \\
& 5 & 1.69 & 0.142 & 0.186 & 0.219 \\
& 50 & 1.59 & 0.134 & 0.175 & 0.206 \\
850 & 0.6 & 2.43 & 0.193 & 0.252 & 0.296 \\
& 2.5 & 1.98 & 0.157 & 0.206 & 0.242 \\
& 5 & 1.69 & 0.134 & 0.175 & 0.206 \\
& 50 & 1.59 & 0.126 & 0.165 & 0.194 \\
900 & 0.6 & 2.43 & 0.182 & 0.238 & 0.280 \\
& 2.5 & 1.98 & 0.148 & 0.194 & 0.228 \\
& 5 & 1.69 & 0.127 & 0.166 & 0.195 \\
& 50 & 1.59 & 0.119 & 0.156 & 0.183 \\
950 & 0.6 & 2.43 & 0.162 & 0.212 & 0.250 \\
& 2.5 & 1.98 & 0.132 & 0.173 & 0.203 \\
& 5 & 1.69 & 0.113 & 0.148 & 0.174 \\
& 50 & 1.59 & 0.106 & 0.139 & 0.163 \\
\hline
\end{tabular}


updates have shown rapid decreases in the Netherlands for modules and inverters, but less so for complete systems and installation cost. This is also seen on the global market. Module prices have been about halved globally over 2012 [3].

The average system price cannot be compared directly with summing up average module price, average inverter price and average installation price. Suppose a house owner would like to purchase a $4 \mathrm{kWp}$ system, which comprises of $16250 \mathrm{Wp}$ modules of $1.26 € / \mathrm{Wp}$, an inverter of $0.35 € / \mathrm{Wp}$. and installation of 0.35 $€ / \mathrm{Wp}$. Total system price would be $1.96 € / \mathrm{Wp}$, which is $10-15 \%$ larger than the system price used in Table 1. Obviously, system installers are able to close better deals on the market than consumers buying individual components.

\section{Conclusion}

In order to follow price developments in the fast growing and dynamic Dutch PV market, four 2012 quarterly inventories of PV modules, inverters, and other BOS components, as well as on complete PV systems have been composed. It has been found that prices of modules, inverters, and systems all have decreased by $44.3,14$, and $7.3-10.2 \%$, respectively. This has lead to a large market growth in 2012, which more than doubled with respect to the installed capacity in 2011. Assessment of grid parity shows that LCOE can be 10-15 cent $€$ lower than current consumer retail price, for systems of typical household size with high-energy yield, i.e., that are properly installed on good locations. Continuation of this market study in 2013 will reveal if a further price reduction can be realized, which will be a challenge in view of the recent EU decision to impose provisional anti-dumping tariffs on Chinese PV panels [4]. Therefore, in our 2013 study we will also distinguish between the countries of origin of the modules [5].

\section{Acknowledgments}

We would like to thank AgentschapNL for financial support.

\section{References}

[1] CBS Statline. http://statline.cbs.nl/statweb/ [accessed 06.04.13].

[2] van Sark WGJHM, Muizebelt P, Cace J, de Vries A, de Rijk P. Grid parity reached for consumers in the Netherlands. In: Proceedings of the 38th IEEE Photovoltaic Specialist Conference; 2012. pp. 2462-6.

[3] Barker M. http://www.displaysearchblog.com/2013/02/pv-c-si-module-aspscontinue-steep-decline-in-2012/ [accessed 06.08.13].

[4] EU Press Release June 4, 2013, EU imposes provisional anti-dumping tariffs on Chinese solar panels, IP/13/501.http://europa.eu/rapid/press-release_IP-13501_en.htm; 2013 [accessed 06.08.13].

[5] van Sark WGJHM, Muizebelt P, Cace J, de Vries A, de Rijk P. Photovoltaic market development in the Netherlands. In: Mine A, Jäger-Waldau A, Helm P, editors. Proceedings of the 28th European Photovoltaic Solar Energy Conference. Munich, Germany: WIP - Renewable Energies; 2013. pp. 4723-6. 